FedUni ResearchOnline

http://researchonline.federation.edu.au

This is an Accepted Manuscript of an article published by Taylor \& Francis in Journal of Computer Information Systems on 11/08/2016, available online: 
To cite this article: Zhaohao Sun, Kenneth David Strang \& Sally Firmin (2016): Business Analytics-Based Enterprise Information Systems, Journal of Computer Information Systems, DOI: 10.1080/08874417.2016.1183977.

\title{
Business Analytics-Based Enterprise Information Systems
}

\author{
Zhaohao Sun* \\ Department of Business Studies \\ PNG University of Technology, Private Mail Bag, Lae 411, Morobe, PNG \\ Phone: +675 4734406 (O), Fax: +675 4757667 \\ zsun@dbs.unitech.ac.pg, zhaohao.sun@gmail.com \\ Kenneth Strang \\ School of Business \& Economics \\ State University of New York, Plattsburgh at Queensbury, NY 12804, USA \\ Phone: 518792 5425, Fax: 5187923868 \\ kenneth.strang@plattsburgh.edu \\ Sally Firmin \\ School of Engineering and Information Technology \\ Federation University Australia, Ballarat, VIC 3353, Australia \\ Phone: +6135327 9739. Fax: +6135327 \\ s.firmin@federation.edu.au
}

*Corresponding author.

zsun@dbs.unitech.ac.pg, zhaohao.sun@gmail.com, kenneth.strang@plattsburgh.edu, s.firmin@federation.edu.au 


\title{
Business Analytics-Based Enterprise Information Systems
}

\author{
Zhaohao Sun, Kenneth Strang, Sally Firmin
}

\begin{abstract}
Big data analytics and business analytics are a disruptive technology and innovative solution for enterprise development. However, what is the relationship between business analytics, big data analytics and enterprise information systems (EIS)? How can business analytics enhance the development of EIS? How can incorporate analytics into EIS? These are still big issues. This paper addresses these three issues by proposing ontology of business analytics, presenting an analytics services-oriented architecture (ASOA) and applying ASOA to EIS, where our surveyed data analysis showed that the proposed ASOA is viable for developing EIS. This paper then examines incorporation of business analytics into EIS through proposing a model for business analytics services-based EIS, or ASEIS for short. The proposed approach in this paper might facilitate the research and development of EIS, business analytics, big data analytics, and business intelligence.
\end{abstract}

Keywords: Business analytics, big data analytics, enterprise information systems, business intelligence, service oriented architecture.

\section{INTRODUCTION}

Digital analytics has emerged as a disruptive technology and innovative solution to the global economy [1]. Business analytics is an emerging and fast-growing field [2]. Big data and its emerging technologies including big data analytics have been not only making fundamental changes in the way the business operates but also making data analytics and business analytics more opportunities for academicians and enterprise CEOs. Business analytics and big data analytics have become a mainstream market adopted broadly across industries, organizations, and geographic regions to facilitate data-driven decision making [3]. For example, business analytics comprises a $\$ 12.2$ billion market [4]. According to a study of Gartner, worldwide BI (business intelligence) and analytics software, consisting of BI platforms, analytic applications and advanced analytics, totalled \$14.4 billion in 2013, an 8 percent increase from 2012 revenue [5]. This fact enhances unprecedented interest and adoption of advanced analytics. According to the annual survey results of $850 \mathrm{CEO}$ and other C-level executives of global organisations, McKinsey [6] concludes in 2014 that $45 \%$ of executives put "big data and advanced analytics" as the first three strategic priorities and spending in three years' time and more than one third of executives will now spend or in three years' time in this area. IDC (International Data Corporation) predicts that the business analytics software market grows at a $9.7 \%$ compound annual growth rate over the next five years from 2012 to 2017 [3]. However, data analysis has been popular in every field over the past two thousand years. What is the relationship between data analysis and data analytics as well as business analytics? This is still a big issue for academic communities.

Enterprise information systems (EIS) have been implemented or adopted in many firms in general and Fortune 500 companies in particular to achieve performance excellence and support decision making over the past few decades [6, p. 381]. EIS are based on organizationwide internal data and big data from the Web. How to use big data and big data analytics for businesses and for improving EIS has become a big challenge for enterprises and development of EIS recently [8,6].

The above brief discussion implies that the following important issues have not drawn significant attention in the scholarly peer-reviewed literature: 
- What is the relationship between business analytics and EIS?

- How can business analytics facilitate the development of EIS and their services?

- How can analytics be incorporated into EIS?

This paper will address these three issues through extending our early research on analytics service oriented architecture for EIS [9]. More specifically, we first propose ontology of business analytics through overviewing our early work on business analytics and big data analytics [9]. To address the second issue, we delve into business analytics as a technology for supporting EIS and analytics role in EIS. To address the third issue, we present an analytics service oriented architecture (ASOA), in which we will also explore which analytics services can be provided for enterprises and EIS. Then this paper will discuss how to apply the proposed ASOA to EIS, where we will show that the proposed ASOA is viable for developing EIS based on our surveyed data analysis. Finally, this paper will address how can business analytics be incorporated into EIS through proposing a model for business analytics services-based EIS.

The remainder of this paper is organised as follows. Section 2 provides fundamentals of big data Analytics and Business Analytics. Section 3 discusses EIS and business analytics. Section 4 presents the ASOA. Section 5 applies proposed ASOA to EIS. Section 6 proposes a model for business analytics services-based EIS. The final sections will discuss the related work and end this paper with some concluding remarks and future work.

\section{AN ONTOLOGY OF BUSINESS ANALYTICS AND BIG DATA ANALYTICS}

This section proposes ontology of business analytics and looks at the interrelationship among data analytics, big data analytics and business analytics.

\section{Understanding Data Analysis and Data Analytics}

Data analysis is defined as "the application of tools and techniques to organize, study, reach conclusions, and sometimes make predictions about a special collection of "data/information/ knowledge" [10]. This definition emphasizes "the application of tools and techniques". Norusis [11] defines data analysis as the "art of examining, summarizing, and drawing conclusions from data". This definition emphasizes the three functions of data analysis: examining data, summarizing data, and drawing conclusions from data. For example, a marketing manager might use data analysis to study the marketing situation based on the sales information in the past quarter and forecast the marketing trend in the coming half a year. A general practitioner usually uses data analysis from the pathologist to diagnose the illness of a patient and prescribe the medicine for the patient.

More generally, data analysis is ubiquitous in almost every organisation and community. Data analysis has been used for thousands of years in human culture. For example, data analysis has played an important role in The Art of War, which was published by Sun Tze 2000 years ago [9]. Data analysis is at the heart of decision making in all business applications [12]. It has been used in every occupation which has professionals who work on data analysis. These professionals can be called analysts, for example, political analyst, systems analyst, financial analyst, and so on.

Data analytics might be the oldest among all types of analytics [13, 14]. Turban and Volonino [7] refer to analytics as a method or technique that uses data, information, and knowledge to learn, describe and predict something. "learn, describe and predict" are all in the above definitions of data analysis, because, "learn and describe" are a part of "organize, 
study", and "predict" is similar to "make predictions", "a method or technique" is in "tools and techniques". This means data analytics is the same as or similar to data analysis. However, data analytics is a new form of data analysis empowered by the current information communication technology (ICT) and Web technology. Based on the above discussion, we can define data analytics as a science and technology about examining, summarizing, and drawing conclusions from data to learn, describe and predict something. "Science and technology" also includes current tools and applications as well as management techniques. Taking into account the close relationship among data, information, and knowledge [15], we can use information analytics or knowledge analytics instead of data analytics when necessary. Briefly, data analytics can be considered as data-driven discoveries and communications [14]. Similarly, information/knowledge analytics can be defined as "information/knowledge-driven discoveries and communications" [9].

From above discussion, we find that data analysis is a more general concept than data analytics. In practice, data analysis might emphasize "analysis" whereas data analytics stresses "analytics"-discovering, modeling, predicting and communicating [9]. Even so, both share the common goal that produces the data analysts as an occupation. Furthermore, data analysis has been in the field of business and management for decades. For example, it has been offered as a course with Microsoft Excel or IBM SPSS (Statistical Package for the Social Sciences) in undergraduate programs of business for decades worldwide $[10,11]$. In contrast to data analysis, data analytics, in particular big data analytics, is an emerging field, and is preferred in the field of computer science, information systems. For example, in recent years, data analytics has been offered as undergraduate or postgraduate programs by universities around the world to meet the increasing needs for data scientist talents. For instance, Bachelor of Data Analytics and Master of Data Analytics are offered at Deakin University Australia [16]. Recently, data analytics and business analytics have been important fields of business, computer science and information systems that are recruiting talent scholars and professionals by many universities in the world.

\section{Fundamentals of Data Analytics}

The fundamentals of data analytics consist of mathematics, statistics, engineering, human interface, and computer science or information technology (IT) [9, 17]. The techniques for data analytics encompass a wide range of mathematical, statistical, and modeling techniques [18]. Data Analytics always involves historical or current data and visualization [19]. This requires analytics to use data mining (DM) to discover knowledge from a data warehouse (DW) or a big database in order to aid decision making, in particular in the text of business and management [7, p. 344]. DM employs advanced statistical tools to analyze the wealth of data including big data available through DWs and other sources to identify possible relationships, patterns and anomalies and discover information or knowledge for rational decision making [18, p. 590]. DM includes web mining and text mining [8]. DW extracts or obtains its data from both operational databases and external sources, providing a more comprehensive data pool including historical or current data [18, p. 590].

Analytics is also required to use statistical modelling (SM) to learn something that can aid decision making [20, p. 183]. Only are these not enough for decision making in general, business decision making in specific, because a business decision maker such as a CEO or a $\mathrm{CFO}$ has no time to read discovered knowledge or patterns in a long text. The C-level executives hope to get succinct and vivid knowledge or patterns in a form of figure or table 
presented as a visual model, or spreadsheet, or dashboards, or scorecards or barometer [19]. They prefer analytics to use visualization technique to make any knowledge patterns and information for decision making in a form of figure or table.

Based on the above discussion, data analytics can facilitate business decision making and realization of business objectives through analyzing current problems and future trends, creating predictive models to forecast future threats and opportunities and analyzing/optimizing business processes based on involved historical or current data to enhance organizational performance [14]. Therefore, data analytics can be succinctly represented below [9].

Data analytics $=$ Data analysis $+\mathrm{DW}+\mathrm{DM}+\mathrm{SM}+$ Visualization 1

This representation reveals the historical relationship between data analysis and data analytics, that is, data analytics is based on data analysis. It is also shown that computer science and IT play a dominant role in the development of data analytics through providing sophisticated techniques and tools of DM, DW and visualization. SM still plays a fundamental role in the development of data analytics, just as in data analysis. Data in the equation can be considered as a variable. If we use web data, information, knowledge, business data, and big data to replace the data in the equation, then we get web (data) analytics, information analytics, knowledge analytics, business analytics, and big data analytics respectively. We can use other kind of data, information and knowledge to replace the data in the equation to get new analytics, for example, social (data) analytics [21].

\section{An Ontology of Business Analytics}

We have looked at data analytics, web analytics, information analytics, knowledge analytics, big data analytics and business analytics in the previous subsection. The relationship of all these analytics can be summarized into ontology of business analytics [9], as illustrated in Figure 1. In this figure, a directed arrow from $A$ to $B$ represents a generalization relationship from $\mathrm{A}$ to $\mathrm{B}$, that is, $\mathrm{B}$ is generalized from $\mathrm{A}$, where $\mathrm{A}$ and $\mathrm{B}$ represent data analysis, data analytics, information analytics, big data analytics, and so on respectively. For example, data analytics is generalized from data analysis by emphasizing the applications of sophisticated techniques, and tools of DM, DW, SM, and visualization (see Equation 1 of Section 2) based on the fundamental theory and methods of data analysis. In other word, data analytics is generalized from data analysis and more powerful than data analysis. The generalization relationship here is similar to that among subclass, class and superclass used in objectoriented technology. For example, we can consider web analytics as a subclass of data analytics.

In the ontology, business analytics is at the top while data analysis is at the bottom. Data analysis is the most general concept that directly generalizes data analytics. In other words, data analysis is a part of any data analytics as shown in Equation 1. All the other analytics including big data analytics can be considered as the generalized and applied form of data analytics and support business analytics. 


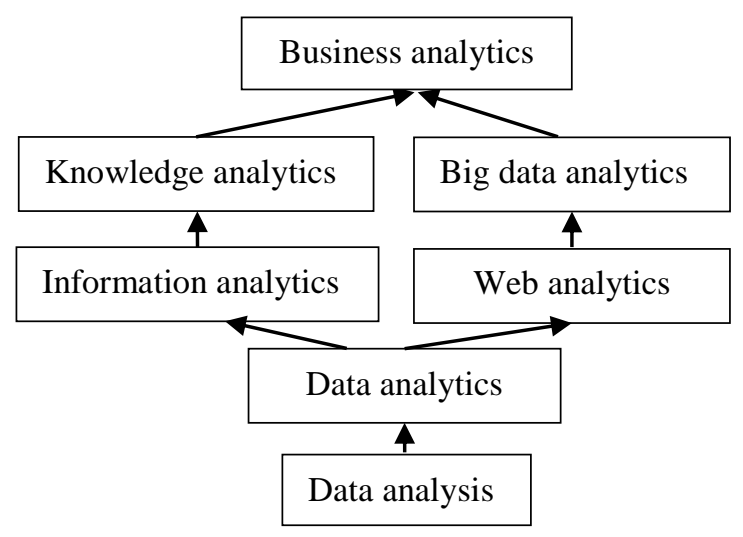

Figure 1. An ontology of business analytics

Data, information, and knowledge have close interrelationships in business and IT [22]. In information technology, information is a proceeded data, while knowledge is proceeded information using skills and expertise of knowledge workers including experts and intelligent systems [9]. Therefore, information can be generalized from data, while knowledge can be generalized from information [16, p. 15]. Similarly, information analytics is generalized from data analytics while knowledge analytics is generalized from information analytics. Big data analytics can be generalized from data analytics and web analytics taking into big data from the Web as one of dominated resources [9], as shown in Figure 1.

It should be noted that many authors call business analytics digital analytics, which is a set of business and technical activities that define, create, collect, verify or transform digital data into reporting, research, analyses, recommendations, optimizations, predictions, and automations [24]. In fact, digital analytics could be a more general form of analytics applying in all activities of computing, because the latter is ubiquitous in the current society. Therefore, digital analytics can include data analytics and web analytics, as well as information analytics, knowledge analytics and big data analytics.

In the following two subsections we will examine big data analytics and business analytics in some detail.

\section{Big Data Analytics}

The dramatic development of the Internet and the Web as well as mobile communications and cloud services since the late 1990s has been making huge amounts of data and information available to everyone in the world. The significant development of social media or social networking services such as Facebook, Twitter, and QQ has produced more big data, and taken us into the big data era and the social big data era. Everyone has been contributing to this big data era proactively through online shopping, email communication, online communication, and social networking etc.

Big data are not only from various databases employed in EIS in the structured form, but also from all the accessible or non-accessible information online in the semi structured and non-structured form. For example, eBay systems process over 100 petabytes of data daily [24]. Big data has become a new form of strategic natural resource for enterprises and EIS, in which EIS should have a strong ability of processing big data [8, p. 133]. The characteristics of big data can be measured by the following five Big-Five attributes (Note that we will 
discuss Big-Ten attributes as the characteristics of big data in another paper): big volume, big velocity, big variety, big mobility, and big details [25].

- Big volume means that data volume is so large that the size of data is terabytes, petabytes, zettabytes, and beyond available on the Web and other data sources.

- Big velocity means that the great amount of data has been arrived at a significant rate.

- Big variety means that the big diversity of sources from which it arrived and the various types of data available to everyone.

- Big mobility means that in the form of mobile devices like smartphones, mobility creates more data and more demands for data [25].

- Big detail means that databases have processed the huge and qualitative change of the data in big detail.

Just data as a resource [24], big data has and will become a strategic resource. Therefore, big data analytics allows enterprises to enhance business performance, efficiencies and guiding decision processes [24]. Big data analytics also provides the most exciting opportunities and challenges for every field from science, government, and industry. It affects the daily lives of people [8, p. 65].

Big data analytics is an integrated form of data analytics and web analytics for big data. According to Beal [26], big data analytics can be defined as the process of collecting, organizing and analyzing big data to discover patterns and other useful information within the big data. Big data analytics is an emerging technology based on thoroughly multidisciplinary advancement of ICT, mathematics, operations research (OR), and decision sciences for big data. The main components of big data analytics include descriptive analytics, predictive analytics and prescriptive analytics, which correspondingly address the three questions in related to big data: when and what happened? What is likely to happen? And what should happen with the best outcome under uncertainty? [27, p. 5]. All these questions are often encountered in almost every part of science, technology, business, management, organization and industry. Mathematics, optimization, machine learning, data mining, cloud computing, statistical modelling, as well as visualization technology, to name a few, are proved fundamentals for research and development of big data analytics [17].

\section{Business Analytics}

Business analytics is an extended form of data analytics or a kind of application of data analytics including big data analytics in business, as shown in Figure 1 (see Section 2.3). Business analytics consists of descriptive, prescriptive and predicative analytics [15]. Descriptive analytics, also called business reporting, addresses what happened, and what is happening? Predicative analytics focuses on forecasting trends by providing a business solution to what will happen, and why will it happen. Prescriptive analytics answers what we should do and why we should do it [15] [8]. SAP, Oracle, IBM, SAS (A suite of analytics software) Institute and Microsoft are worldwide top five BI and analytics software vendors in 2012-2013 [5].

Business analytics has long been studied in business schools in terms of operations research, management science, simulation analysis, econometrics, and financial analysis [4]. Technological aspects of business analytics are rooted in the decision support systems [4]. However, business analytics has other roots, besides mathematics, information technology, and operations research [9]. The business data may be non-numeric, and their business solutions may rely on qualitative analysis, logic, reasoning, collaboration and negotiation. 
Therefore, business analytics is rooted in the theory, technologies, systems and tools to support decision making through providing powerful mechanisms for discovering, acquiring, generating, assimilating, selecting, and emitting data, information (corresponding to information analytics) and knowledge (corresponding to knowledge analytics) [4].

\section{ENTERPRISE INFORMATION SYSTEMS AND BUSINESS ANALYTICS}

This section examines enterprise information systems and its relationships with business analytics.

\section{Enterprise Information Systems}

Enterprise information systems (EIS) have drawn increasing attention in academia, organizations and enterprises over the past few decades. EIS are also called enterprise systems [8]. There are many different definitions on EIS. For example, EIS refer to as

1.Systems that help managers and companies to improve their performance by enabling them to seamlessly share data and information among departments and with external business partners [7, p. 287]. These systems integrate the functional systems such as accounting, finance and marketing as well as operations.

2.Enterprise software based on a suite of integrated software modules and a common central database [6, p. 363].

3.Information systems that support activities in multiple departments of an enterprise [28, $\mathrm{p}$. 605].

The first definition is a self-contained one for EIS and emphasizes sharing data and information. The second stresses enterprise software with a common central database. The third one is a most general definition. Combining these three definitions, we can define an EIS as an information system that has a common central database and supports activities in multiple departments of the enterprise through integrating the functional information systems (IS) such as accounting IS, finance IS and marketing IS as well as operations IS, and accessing the resources available on the Web. The support activities include help managers and companies to improve their business performance and decision making by enabling them to seamlessly share data and information among departments and with external business partners [9].

EIS mainly consist of ERP (enterprise resource planning) systems, SCM (supply chain management) systems, CRM (customer relationship management) systems and knowledge management (KM) systems [7, 6]. The main EIS vendors, for example, SAP Business Suite, Oracle's e-Business Suite and Microsoft's Dynamics Suite, have used enterprise solutions and enterprise suite to make these EIS work closely each other and link to systems of customers and suppliers based on web services, cloud services and service-oriented architecture (SOA) [6, p. 383].

\section{Business Analytics and EIS}

Based on the previous subsection's discussion, data analytics can facilitate the development of EIS, because it can support business decision making with valuable data, information and knowledge [9]. Both EIS and data analytics are common in emphasizing the data as a strategic resource for the development of enterprises [12], in particular for global enterprises. EIS involves interactive visualization for data exploration and discovery [29], which can be considered as a part of big data analytics, as mentioned in Equation 1 of Section 2.2. EIS include analytical tools for using data captured by the system to evaluate the business and 
marketing performance [6, p. 366]. The analytical tools are a fundamental part of any business analytics systems, as mentioned in Section 2.5. This implies that EIS and business analytics share some common tools to support business decision making and improve the business performance of enterprises.

Currently, enterprises' development is heavily relied on four cutting-age technology pillars: cloud, mobile, big data and social technologies. Each of these pillars corresponds to a special kind of web services, that is, cloud services, mobile services, big data services and social networking services [20]. Each of these services is becoming an inevitable component of any EIS. Each of these services has been supported by data analytics services and technologies [9], as shown in Figure 2.

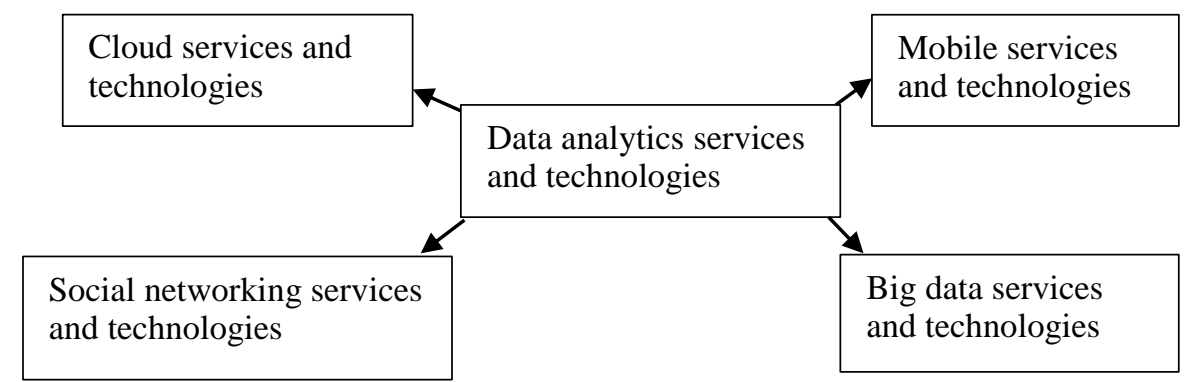

Figure 2. Analytics services support EIS

In Figure 2, web searches belong to cloud services and technologies. The big data services rely on the Internet infrastructure, if they are related to the web; otherwise, the big data services rely on hardware systems and information systems. For example, the CCTV (Closedcircuit television) of a metropolis collects real-time big data on traffic, security and other social events of the city, which will be processed by information systems to provide big data services to help maintain the surveillance and security of the city and safety of residents.

Based on IDC's research in 2015 [31], the big data technology and services market represents a fast-growing multibillion-dollar worldwide opportunity, and will grow at a $26.4 \%$ compound annual growth rate to $\$ 41.5$ billion through 2018 , or about six times the growth rate of the overall IT market. This means that big data analytics services and technologies have become an important emerging market, together with big data services, cloud services, mobile services and social networking services [19]. All these four services and the technologies have shaped the most important market for IT and EIS development [9].

Furthermore, business analytics is a pivotal part for developing EIS [9]. From a technological viewpoint, business analytics is data-driven business oriented technique and facilitates business decision making and then improves EIS as a system component. From a data viewpoint, business analytics relies on data analytics; data and big data have become a strategic resource for organizations and enterprises, in particular for multinational organisations and EIS. Discovering useful patterns, information and knowledge from data bases, data warehouses, data marts and the Web has become the central topics both for business operations and EIS [7]. This is just the task of business analytics. 


\section{ANALYTICS SERVICE ORIENTED ARCHITECTURE}

This section proposes an analytics service oriented architecture (ASOA) and then examines each of the main players in the ASOA. One of the major challenges in big data analytics is to specify overall system architecture [32, p. 146]. ASOA is one addressing this challenge.

The service-oriented architecture (SOA) is fundamental for web services [30]. SOA includes three players and three fundamental operations for any web services. The three players are service provider, service requestor and service broker [31]. The service provider is the owner of the web service. The service requestor is the customer or consumer of the web service. The service broker is an intermediary that facilitates the discovery, selection, composition, consultation, recommendation, transfer or delivery of web services from the service provider to the service requestor [32]. The three fundamental operations are publish, find, and bind [9].

- Publish operation: The service provider publishes the web service to the service broker.

- Find operation: The service requestor finds web services from the service broker.

- Bind operation: The service requestor invokes the found web services from the service provider.

As an application of the SOA, the rest of this section proposes an ASOA by specialising general services as analytics services, as showing in Figure 3.

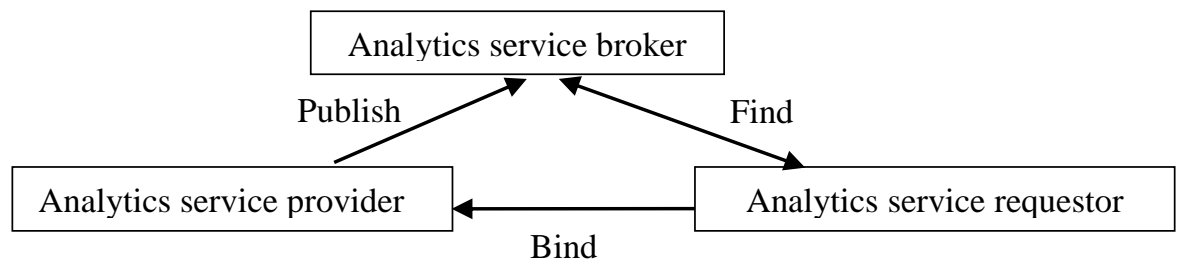

Figure 3. ASOA: An analytics SOA

In this ASOA, the service provider is analytics service provider. The service requestor is analytics service requestor. The service broker is analytics service broker. In what follows, we will look at each of these in some detail, taking into account BI and EIS.

Analytics service requestors include organizations, governments and all level business decision makers such as CEOs, other C-level executives as well as managers [9]. Analytics service requestors require data analytics services, big data analytics services, information analytics services, knowledge analytics services, business analytics services with visualization technique to make any knowledge patterns and information for decision making in a form of figure or table or report [13]. More generally, analytics service requestors include anyone who likes to make any decision or acquires information based on analytical reports provided by the analytics service provider. Therefore, a person with smartphone receiving analytics services is also an analytics service requestor [14].

Analytics service brokers are all the entities that facilitate the provision of analytics services and development of analytics services. Public presses, traditional media and social media, consulting companies, scholars and university students, EIS, etc are examples of analytics service brokers [9]. All these use a variety of methods and techniques to improve the better provision and understanding of analytics and analytics services in general and data analytics, business analytics, web analytics and big data analytics and their services in 
particular. All these have been offered to university students as a course material or content in business and computing areas to some extent in recent years. McKinsey Consulting (http://www.mckinsey.com/) and Boston Consulting Group (BCG) as analytics service brokers have played an important role in pushing analytics in businesses and enterprises, just as they promote "big data". Gartner and IDC are also famous analytics service brokers in the world [33].

Analytics service providers include analytics developers, analytics vendors, analytics systems or software and other intermediaries that can provide analytics services [9]. Analytics developers provide analytic tools with extensive data extraction, analytics and reporting functionality such as Piwik, CrawlTrack [35, 36]. Application service providers (ASPs) can also provide web analytics in a hosted ASP model with quicker implementation and lower administrative costs [34]. Recently, web analytics service (WAS) providers are important analytics service providers. A WAS provider, for example, Adobe Marketing Cloud (http://www.adobe.com/au/solutions/digital-marketing.html), aggregates and analyses blog data about the online behaviours of users who visited the client's website, then they evaluate a variety of analytical reports concerning the client's customer online behaviours that the client wishes to understand, this can then facilitate their strategic business decision making [34]. Google is not only a search engine provider, but also a WAS vendor, because Google provides Google Analytics (http://www.google.com/analytics/) with good tracking tools. In fact, most hosting websites also provide these similar analytics services as well.

A mobile phone company is an intermediary that can provide analytics services to the customers with smartphone [14]. For example, Mobile App Analytics (http://www.google.com/analytics/mobile/) is a part of Google Analytics. It is also a mobile analytics services provider that helps the smartphone customers to discover new and relevant users through traffic sources reports. Mobile App Analytics plays a constructive role in integration, and gets engaged through event tracking and flow visualization. It also sets and tracks the goal conversions one wants most: purchases, clicks, or simply time spent on the App.

More generally, many information systems including EIS have contained an analytics App as a system component to generate table, diagram or report. All these kinds of information systems can be considered as analytics service providers. For example, predicative analytics, a part of big data analytics, is a component of web mining systems that sifts through data to identify patterns of e-customer behaviours that predict which offers customers might respond to in the future or which customers the company may be in danger of losing in the near future [7, p. 345]. The big data analytics services providers on the Web include Amazon, Google and Microsoft [37].

\section{APPLYING ASOA TO EIS}

This section addresses how to apply the proposed ASOA to EIS in some detail taking into account a model for applying ASOA to EIS [9], as shown in Figure 4. 


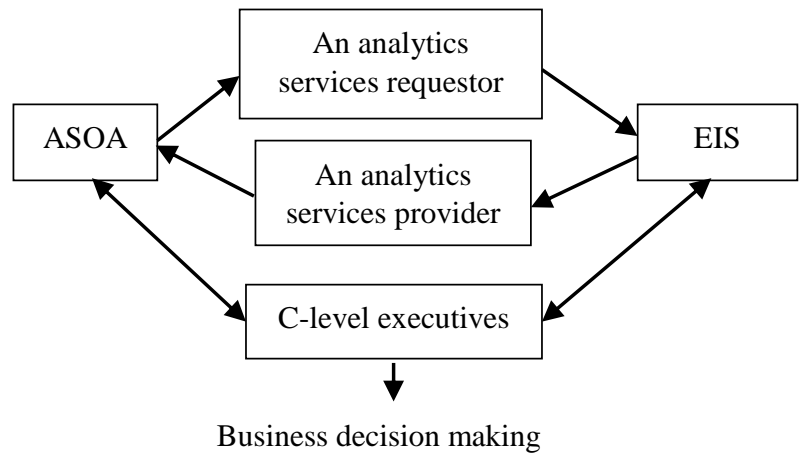

Figure 4. A model for applying ASOA to EIS

Analytics as a Service (AaaS) is a relatively new concept that has emerged as a rapidly growing business sector of web analytics industry, which provides efficient web log analytic services for firm-level customers [20] [39]. AaaS or analytics services, as discussed in the ASOA above, are provided by an individual or organization or information system including EIS that uses a wide range of analytic tools or apps wherever they may be located [14]. AaaS has the ability to turn a general analytic platform into a shared utility for an enterprise with visualized analytic services [36]. AaaS model has been adopted by many famous web companies such as Amazon, Microsoft, and eBay [9]. The key reason behind this is that the traditional hub-and-spoke architectures cannot satisfy the demands driven by increasingly complex business analytics [36]. AaaS promises to provide decision makers (often through EIS or other intelligent systems) with visualising much needed information and knowledge [14].

As previously defined, EIS support business decision making with valuable data, information and knowledge. ASOA is an architecture for supporting business decision making with analytics services. The theory of analytics providers, analytics brokers and analytics requestors of the ASOA can facilitate the understanding and development of EIS and business decision making. For example, from a deep analysis of the ASOA, an enterprise and its CEO can know who are the best analytics providers and brokers in order to improve his business, market performance, and competition.

An EIS can be considered as an analytics services requestor of the ASOA in order to improve its performance, on the one hand. For example, big data analytics might be incorporated into an existing EIS in order to meet the enterprise requirement for the business analytics and big data analytics. In this way, the upgraded EIS will have more powerful performance for enterprise's data processing and support ability for business decision making [9]. On the other hand, an EIS can be considered as an analytics service provider of the ASOA, because an advanced EIS can provide analytics services to enterprises and its C-level executives for business decision making. The analytics services might include weekly/monthly/quarterly visualized market trend report, online customer comments summary and analysis report [21].

Business analytics as a system component in an EIS can monitor data generated in business operations so as to analyse performance based on key indicators and present the analysis results to a wide range of users in a visual way [12]. The incorporation of business analytics into the existing EIS can allow CEOs and other managers of the enterprise to use 
the output of business analytics, as a service, to make decisions in the corresponding business processes such as marketing, SCM, CRM and so on [12].

We surveyed 71 IT managers at the Association for Education in Journalism and Mass Communication (AEJMC) in Montreal during August 6-9, 2014, to collect data concerning the enterprise-level acceptability of the ASOA concept. These results indicate some preliminary support for the ASOA concept of having service brokers work with service requesters and providers similar to the way private mortgage and loans work in the USA [9]. Based on this preliminary enterprise acceptability of this ASOA model, we propose that more research be done to investigate how it could be used.

\section{ASEIS: AN ANALYTICS SERVICES-BASED EIS}

As an application of ASOA to EIS, this section propose a model for analytics services-based EIS, or ASEIS for short.

As we know, standalone enterprise systems are becoming a thing of the past [38, p. 382]. The proposed ASEIS will incorporate analytics services into an integrated EIS that consists of main functions of SCM systems, CRM systems and KM systems, as shown in Figure 5. In what follows, we will examine this model in some detail.

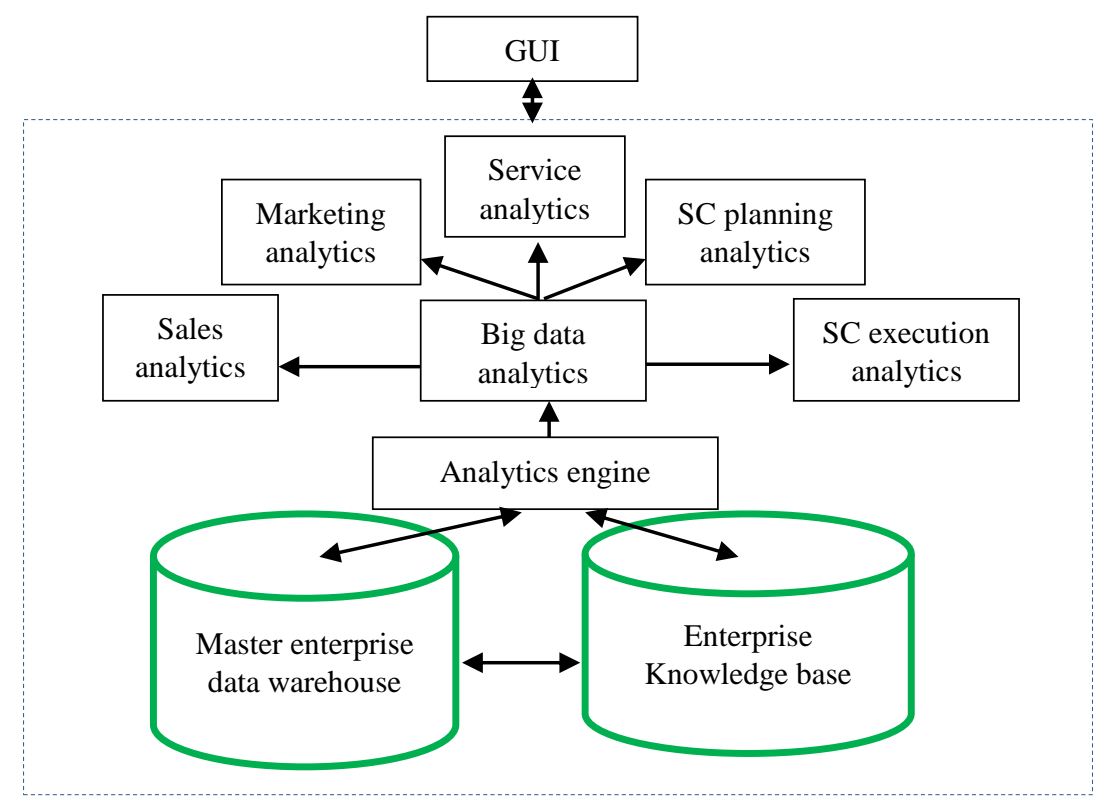

Figure 5. A model for analytics based EIS

SCM systems are classified as either SC (supply chain) planning systems or SC execution systems [7, p. 370]. Then SC planning and SC execution are main functions of SCM systems. CRM systems mainly consist of sales, marketing and services [7, p. 379]. A KM system mainly consists of create, capture, refine, store, manage, disseminate and share knowledge [7, p. 314]. Thus, the proposed ASEIS includes SC planning analytics, SC execution analytics, marketing analytics, sales analytics, service analytics and big data analytics taking into knowledge analytics (see Section 2).

Master enterprise data warehouse (MEDW) mainly consists of data related to sales, marketing, services, customers, SC (supply chain) planning and SC execution flowing from department of marketing, human resources, and other data related to departments. Enterprise 
14

knowledge base (EKB) consists of information and knowledge from the Web, call center, direct mail, email, retail store, and client and partner [6].

Big data analytics is based on MEDW and EKB and provides related knowledge and information for sales analytics, marketing analytics, service analytics, SC planning analytics and SC execution analytics.

Analytics engine is a mechanism for managing and producing SC planning analytics, SC planning analytics, marketing analytics, service analytics, customer analytics and big data analytics as well as knowledge analytics. Based on the foregoing equation (1), Analytics engine has OLAP, data mining, statistical modelling, optimization, visualisation tools and other data and knowledge analysis tools based on the techniques including soft computing, machine learning, fuzzy neural networks, decision trees, and probabilistic models [38, p. 380, 12].

\section{RELATED WORK AND DISCUSSION}

We have mentioned a number of scholarly researches on data analysis, data analytics, big data analytics, EIS. In what follows, we will focus on related work and discussion ontology, extension of SOA, and the work of SAP as well as incorporation of analytics services into EIS.

A basic search in Scopus and Google scholar (i.e. article title and key words) reveals that the number of papers published on "big data analytics Enterprise system" (in the title of papers) in journals and proceedings is few (retrieved on 8 April 2015). This motivates our research to explore big data analytics for EIS.

Ontology has been important in computer science and artificial intelligence, although it is originally from philosophy [9]. From a viewpoint of computer science, the key behind the ontology is the interrelationship among related concepts underpinning an emerging field [9]. Thus, we try to explore the interrelationship among many analytics related to business analytics in order to develop ontology of business analytics and analytics-based EIS. In fact, we recently find that there are a web of analytics, besides what we mentioned, including marketing analytics, and social analytics [21], Twitter analytics, Pinterest analytics, blackboard education data analytics, to name a few. These also motivate us to investigate the ontology of business analytics and the foregoing analytics equation.

The result reported in this paper on ontology of business analytics and analytics equation is only a beginning for providing a relatively comprehensive ontology of business analytics. To this end, we will investigate more literature or academic reviewed sources as a future work to develop ontology of business analytics with five levels of knowledge concepts for each involved analytics. In other words, for each analytics in the ontology of business analytics, we will examine its concepts, fundamentals, methodologies, tools and applications. Such an investigation would become an important guide for the research and development of business analytics, big data analytics, and EIS.

Since its inception in 1999-2000 [39], SOA has been evolved significantly along three directions. In the first direction, SOA has been evolved by adding more operations to the SOA. For example, Papazoglou [40] proposes an extended SOA by adding many new operations including discovery, selection, assurance, support, and coordination.

In the second direction, SOA has been evolved by adding or detailing the main players to the SOA. For example, Sun, Dong, and Yearwood [31] specify services into web services and examine the web service providers, requestors, and brokers. Service provider, service 
aggregator, service client, market maker, and service operator are involved in the extended SOA presented by Papazoglou and Georgakopoulos [41].

The third direction is to provide more sophisticated computing techniques and intelligent techniques to understand fundamental operations and automate the roles of the three players in the SOA using intelligent agents [30]. For example, an activity or operation of web services is usually implemented by a few intelligent agents within a multiagent web service system [15]. Therefore, more and more intelligent agents will be involved in web services with the development of automating activities of web services [31]. Some behaviour operations of web service agents are also fundamentally important to make web services successful. These fundamental behaviours include communication, interaction, collaboration, cooperation, coordination, negotiation, trust and even deception on the web [31]. Our proposed work on ASOA is a specialisation of the mentioned SOA in analytics service and will facilitate the research and development of analytics services based EIS.

SAP has introduced its enterprise service-oriented architecture [6, p. 383]. The key idea of this architecture is similar to our presented ASOA, because both specify general services to special services. SAP' architecture specifies general services to enterprise services whereas our ASOA specifies general services to analytics services. Analytics services should be a part of enterprise services, and then our ASOA can be considered as concrete applications for the enterprise service-oriented architecture of SAP. SAP has incorporated mentioned enterprise SOA into its next generation EIS [6]. However, SAP's EIS focus on key applications in finance, logistics, procurement and human resources management as an ERP system. We conceive that our ASOA will be incorporated into the next generation EIS integrating SCM, CRM and KM systems, in particular the cloud-based version of EIS. This is the motivation of our proposed ASEIS: An Analytics Services-based EIS.

\section{CONCLUSION}

This paper proposed an ontology of business analytics through examining the interrelationship among data analysis, data analytics, business analytics and big data analytics. The proposed ontology of business analytics reveals that big data analytics is an advanced form of data analytics taking into account big data while business analytics is a technique for applying big data analytics and big data as a service to businesses. This paper then presented a model for an analytics services-based EIS (ASEIS) through looking at business analytics as a technology and service for supporting EIS, and proposing an analytics service oriented architecture (ASOA). ASEIS integrates external data with internal organizational data of enterprises, which is one of the significant issues for successful adoption of EIS in enterprises. The preliminary analysis on the collected data shows that this proposed ASOA is viable for facilitating the development of EIS. The discussion of the ASEIS and the work of SAP implies that the ASEIS is useful for developing the next generation of EIS in the big data era.

In the future work, we will analyse the foregoing collected data vigorously and explore enterprise acceptability of ASOA for EIS. The implications of big data analytics for enterprises are new platforms, new roles and new techniques [42]. Thus, we will also conduct a survey to validate the ASEIS, and explore how to implement ASEIS based on big data analytics. Finally, how the components of the enterprise can be analysed by the analytics services? What should the main functions of EIS be integrated with big data analytics? How can we develop big data analytics services-centred EIS in order to integrate the above 
16

mentioned EIS? These are still three big challenges for developing analytics services-centred EIS in the future.

\section{ACKNOWLEDGMENTS}

We gratefully thank the anonymous reviewers for their erudite comments which allowed us to improve the quality of this paper.

\section{REFERENCES}

[1] IDC, "IDC Predictions 2014: Battles for Dominance — and Survival — on the 3rd Platform," Dec 2013. [Online]. Available: http://www.idc.com/getdoc.jsp?containerId=244606. [Accessed 132 2014].

[2] J. Liebowitz, "Business Analytics and Decision-Making: The Years Ahead," The World Financial Review, 28 May 2014.

[3] D. Vesset, B. McDonough, D. Schubmehl and M. Wardley, "Worldwide Business Analytics Software 2013-2017 Forecast and 2012 Vendor Shares (Doc \# 241689)," 6 2013. [Online]. Available: http://www.idc.com/getdoc.jsp?containerId=241689. [Accessed 286 2014].

[4] C. Holsapplea, A. Lee-Postb and R. Pakath, "A unified foundation for business analytics. " Decision Support Systems, vol. 64, p. 130-141, 2014.

[5] R. van der Meulen and J. Rivera, "Gartner Says Worldwide Business Intelligence and Analytics Software Market Grew 8 Percent in 2013," 294 2014. [Online]. Available: http://www.gartner.com/newsroom/id/2723717. [Accessed 286 2014].

[6] McKinsey, "The digital tipping point: McKinsey Global Survey results," June 2014. [Online]. Available: http://www.mckinsey.com/insights/business_technology/the_digital_tipping_point_mckinsey_global_survey_results. [Accessed 17 2014].

[7] K. G. Laudon and K. C. Laudon, Management Information Systems: Managing the Digital Firm (12th Ed), Harlow, England: Pearson, 2012.

[8] J. Liebowitz, Big Data and Business Analytics, Hoboken: CRC Press , 2013.

[9] Z. Sun, K. Strang and J. Yearwood, "Analytics service oriented architecture for enterprise information systems," in Proceedings of iiWAS2014, CONFENIS 2014, 4 - 6 Dec 14, Hanoi, 2014.

[10] P. McFedries, Excel Data Analysis: Yoru visual blueprint for analyzing data, charts, and pivotTables (4th edition), Indianapolis, IN: Visual, 2013.

[11] M. J. Norusis, SPSS: SPSS 7.5 Guide to Data Analytics, Prentice Hall: Upper Saddle River, NJ, 1997.

[12] B. Azvine, D. Nauck and C. Ho, "Intelligent Business Analytics — A Tool to Build Decision-Support Systems for eBusinesses," BT Technology Journal, pp. 21(4), pp.65-71, 2003.

[13] R. J. Kauffman, J. Srivastava and J. Vayghan, "Business and data analytics: New innovations for the management of e-commerce," Electronic Commerce Research and Applications, vol. 11 , p. 85-88, 2012.

[14] D. Delena and H. Demirkanb, "Data, information and analytics as services," Decision Support Systems, vol. 55, no. 1, p. 359-363, 2013.

[15] E. Turban and L. Volonino, Information Technology for Management: Improving Strategic and Operational Performance (8th Edition), Danvers, MA: Wiley \& Sons, 2011.

[16] Z. Sun and G. Finnie, Intelligent Techniques in E-Commerce: A Case-based Reasoning Perspective, Heidelberg Berlin: Springer-Verlag, 2004; 2010.

[17] Deakin, "Business analytics," 2014. [Online]. Available: http://www.deakin.edu.au/study-at-deakin/find-acourse/business-analytics. [Accessed 286 2014].

[18] C. P. Chen and C.-Y. Zhang, "Data-intensive applications, challenges, techniques and technologies: A survey on Big Data," Information Sciences, vol. 275 , p. 314-347, 2014.

[19] C. Coronel, S. Morris and P. Rob, Database Systems: Design, Implementation, and Management (11th edition), Boston: Course Technology, Cengage Learning, 2015.

[20] Z. Sun and J. Yearwood, "A theoretical foundation of demand-driven web services," in Demand-Driven Web Services: Theory, Technologies, and Applications, IGI-Global, 20014, pp. 1-25.

[21] G. P. Schneider, Electornic Commerce (10th Edition), Australia: Coourse Technology Cengage Learning, 2013. 
[22] R. Y. Lau, C. Li and S. S. Liao, "Social analytics: Learning fuzzy product ontologies for aspect-oriented sentiment analytics," Decision Support Systems, vol. 65 , p. 80-94, 2014.

[23] D. Chaffey, Business Information Management (2nd Edn), Harlow England: Prentice Hall, 2011.

[24] J. Phillips, Building a Digital Analytics Organization, Financial Times Press. pp. 7-8, 2013.

[25] K. Kambatla, G. Kollias, V. Kumar and A. Grama, "Trends in big data analytics," Journal of Parallel and Distributed Computing, vol. 74 , no. 7, p. 2561-2573, 2014.

[26] J. Betser and D. Belanger, "Architecting the enterprise with big data analytics," in Big Data and Business Analytics, Boca Raton, FL, CRC Press , 2013, pp. 1-20.

[27] V. Beal, "Big data analytics," 2014. [Online]. Available: http://www.webopedia.com/TERM/B/big_data_analytics.html. [Accessed 208 2014].

[28] M. Minelli, M. Chambers and A. Dhiraj, Big Data, Big Analytics: Emerging Business Intelligence and Analytic Trends for Today's Businesses, Wiley \& Sons (Chinese Edition 2014), 2013.

[29] D. Kroenke, D. Bunker and D. Wilson, Exerperiencing MIS (3rd Edition), Australia: Person, 2014.

[30] A. Brust, "Gartner releases 2013 BI Magic Quadrant," 2013. [Online]. Available: http://www.zdnet.com/gartnerreleases-2013-bi-magic-quadrant-7000011264/. [Accessed 142 2014].

[31] IDC, "Big Data \& Analytics," 2015. [Online]. Available: https://www.idc.com/prodserv/4Pillars/bigdata. [Accessed 18 2015].

[32] National Reserch Council, Frontiers in Massive Data Analysis, Washington: The National Research Press, 2013.

[33] M. P. Papazoglou, Web Services: Principles and Technology, Harlow, England: Pearson Prentice Hall, 2008.

[34] Z. Sun, D. Dong and J. Yearwood, "Demand Driven Web Services," in Service Intelligence and Service Science: Evolutionary Technologies and Challenges, Hershey PA, IGI Global, 2011, pp. 35-55.

[35] R. Tabein, M. Moghadasi and A. Khoshkbarforoushha, "Broker-based Web service selection using learning automata," in 2008 International Conference on Service Systems and Service Management, June July 2008, pp.1-6, 2008.

[36] H. Demirkan and D. Delen, "Leveraging the capabilities of service-oriented decision support systems: Putting analytics and big data in cloud," Decision Support Systems, vol. 55, no. 1, pp. 412-421, 2013.

[37] E. Loukis, K. Pazalos and A. Salagara, "Transforming e-services evaluation data into business analytics using value models," Electronic Commerce Research and Applications, vol. 11, no. 2, pp. 129-141, 2012.

[38] K. C. Laudon and C. G. Traver, E-Commerce 2013: Business, Technology, Society, Harlow, England: Pearson, 2013.

[39] J. Park, J. Kim and J. Koh, "Determinants of continuous usage intention in web analytics services," Electronic Commerce Research and Applications, vol. 9, no. 1, pp. 61-72, 2010.

[40] G. S. Erikson and H. N. Rothberg, "Competitors, intelligence, and big data," in Big Data and Business Analytics, Boca Raton, FL: CRC Press, 2013.

[41] K. Laudon and J. Laudon, Management Information Systems-Managing the Dgital Firm, Boston: Person, 2012.

[42] H. Kreger, "Web Services Conceptual Architecture (WSCA 1.0)," 2001. [Online]. Available: http://www.cs.uoi.gr/ zarras/mdw-ws/WebServicesConceptualArchitectu2.pdf. [Accessed 278 2013].

[43] M. P. Papazoglou, "Service -oriented computing: Concepts, characteristics and directions. In Proceedings of 4th Intl Conf on Web Information Systems Engineering (WISE2003). pp. 3-12.," 2003.

[44] M. P. Papazoglou and D. Georgakopoulos, "Service-orented computing," The Communications of the ACM, vol. 46, no. 10 , pp. $25-28,2003$.

[45] D. Dietrich, "Big Data Analytics," EMC Academic Alliance, 2013. [Online]. Available: https://www.youtube.com/watch?v=d1PHKCc1fog. [Accessed 32 2014]. 